\title{
Randomized clinical study using xenograft blocks loaded with bone morphogenetic protein-2 or autogenous bone blocks for ridge augmentation - a three-dimensional analysis
}

Thoma, Daniel S ; Bienz, Stefan P ; Payer, Michael ; Hüsler, Jürg ; Schmidlin, Patrick R ; Hämmerle, Christoph H F ; Jakse, Norbert ; Jung, Ronald E

\begin{abstract}
OBJECTIVES: To test whether or not the use of a xenogeneic block loaded with rhBMP2 results in superior radiological and profilometric outcomes compared to an autogenous bone block. MATERIALS AND METHODS: Twenty-four patients randomly received a xenogeneic block loaded with rhBMP-2 (test) or an autogenous bone block (control) for primary augmentation. The ridge width (RW) was evaluated by means of a CBCT scan after augmentation surgery and at 4 months, prior to implant placement. Surface scans were taken prior to augmentation and at 4 months for profilometric analyses. Data were analyzed with Wilcoxon-signed rank test, Mann-Whitney test, or nonparametric ANOVA models. RESULTS: The median RW after augmentation amounted to $7.13 \mathrm{~mm}(\mathrm{Q} 1=6.02 ; \mathrm{Q} 3=8.47)$ for test and $6.86 \mathrm{~mm}(\mathrm{Q} 1=5.99 ; \mathrm{Q} 3=8.95)$ for control. During 4 months of healing, the total RW decreased statistically significantly and measured $5.35 \mathrm{~mm}(\mathrm{Q} 1=4.53$; $\mathrm{Q} 3=6.7)$ for test and $5.15 \mathrm{~mm}$ $(\mathrm{Q} 1=3.57 ; \mathrm{Q} 3=7.24)$ for control $(\mathrm{p}=0.0005)$. The differences between the groups were not statistically significant $(\mathrm{p}>0.5899)$. The buccal soft tissue contour slightly increased for test $(0.83 \mathrm{~mm} ; \mathrm{Q} 1=0.62$; $\mathrm{Q} 3=1.87)$ and control $(1.16 \mathrm{~mm} ; \mathrm{Q} 1=0.50 ; \mathrm{Q} 3=1.44)$. CONCLUSIONS: Both treatment modalities successfully increased the ridge width to a similar extent. The shrinkage during healing was not greater in the test than in the control group. The impact of hard tissue augmentation on the soft tissue contour was, however, minimal.
\end{abstract}

DOI: https://doi.org/10.1111/clr.13492

Posted at the Zurich Open Repository and Archive, University of Zurich

ZORA URL: https://doi.org/10.5167/uzh-171616

Journal Article

Accepted Version

Originally published at:

Thoma, Daniel S; Bienz, Stefan P; Payer, Michael; Hüsler, Jürg; Schmidlin, Patrick R; Hämmerle, Christoph H F; Jakse, Norbert; Jung, Ronald E (2019). Randomized clinical study using xenograft blocks loaded with bone morphogenetic protein-2 or autogenous bone blocks for ridge augmentation - a three-dimensional analysis. Clinical Oral Implants Research, 30(9):872-881.

DOI: https://doi.org/10.1111/clr.13492 


\section{Randomized clinical study using xenograft blocks loaded with bone morphogenetic protein-2 or autogenous bone blocks for ridge augmentation - a three-dimensional analysis}

Daniel S. Thoma ${ }^{1}$, Stefan P. Bienz ${ }^{1}$, Michael Payer ${ }^{2}$, Jürg Hüsler ${ }^{1}$, Patrick R. Schmidlin ${ }^{3}$, Christoph H.F. Hämmerle ${ }^{1}$, Norbert Jakse², Ronald E. Jung ${ }^{1}$

Key words: dental implants, bone regeneration, bone morphogenetic protein 2 (MeSH terms) autogenous bone block, guided bone regeneration, $C B C T$

Running title: rhBMP-2 volume

Number of figures: 4

Number of tables: 1

Address for correspondence: $\quad$ PD Dr. Daniel S. Thoma Clinic of Fixed and Removable Prosthodontics and Dental Material Science Center of Dental Medicine, University of Zurich Plattenstrasse 11 $\mathrm{CH}-8032$ Zurich, Switzerland Phone: +41446344256

Fax: +41446344305

e-mail: daniel.thoma@zzm.uzh.ch

${ }^{1}$ Clinic for Fixed and Removable Prosthodontics and Dental Material Science, University of Zurich, Zurich, Switzerland

2 Department of Oral Surgery and Radiology, School of Dentistry, Medical University Graz, Graz, Austria

${ }^{3}$ Clinic of Preventive Dentistry, Periodontology and Cariology, University of Zurich, Zurich, Switzerland 


\section{Conflict of interest and source of funding statement}

The study was supported by a grant from the Osteology Foundation, by Geistlich Pharma AG and Dentsply-Sirona. The study group further reports grants and lecture fees from Geistlich Pharma AG and from Dentsply-Sirona outside of the submitted work. 


\section{Abstract}

Objectives: To test whether or not the use of a xenogeneic block loaded with rhBMP-2 results in superior radiological and profilometric outcomes compared to an autogenous bone block.

Materials and methods: Twenty-four patients randomly received a xenogeneic block loaded with rhBMP-2 (test) or an autogenous bone block (control) for primary augmentation. The ridge width (RW) was evaluated by means of a CBCT scan after augmentation surgery and at 4 months, prior to implant placement. Surface scans were taken prior to augmentation and at 4 months for profilometric analyses. Data was analyzed with Wilcoxon-signed rank test, MannWhitney test or nonparametric ANOVA models.

Results: The median RW after augmentation amounted to $7.13 \mathrm{~mm}(\mathrm{Q} 1=6.02 ; \mathrm{Q} 3=8.47)$ for test and $6.86 \mathrm{~mm}(\mathrm{Q} 1=5.99 ; \mathrm{Q} 3=8.95)$ for control. During 4 months of healing, the total RW decreased statistically significantly and measured $5.35 \mathrm{~mm}(\mathrm{Q} 1=4.53 ; \mathrm{Q} 3=6.7)$ for test and $5.15 \mathrm{~mm}(\mathrm{Q} 1=3.57 ; \mathrm{Q} 3=7.24)$ for control $(\mathrm{p}=0.0005)$. The differences between the groups were not statistically significant $(p>0.5899)$. The buccal soft tissue contour slightly increased for test $(0.83 \mathrm{~mm} ; \mathrm{Q} 1=0.62 ; \mathrm{Q} 3=1.87)$ and control $(1.16 \mathrm{~mm} ; \mathrm{Q} 1=0.50 ; \mathrm{Q} 3=$ 1.44).

Conclusions: Both treatment modalities successfully increased the ridge width to a similar extent. The shrinkage during healing was not greater in the test than in the control group. The impact of hard tissue augmentation on the soft tissue contour was however minimal. 


\section{Introduction}

Due to resorption and remodeling processes following tooth extraction, the ridge contour decreases based on a loss of hard and soft tissue volume. In case of an insufficient ridge width for implant placement, a primary augmentation by means of an autogenous bone block is considered to be the gold standard (Adell, et al., 1990; Keller, Tolman, Eckert, 1999; Nystrom, Nilson, Gunne, Lundgren, 2009; Rocchietta, et al., 2016). Autogenous bone can be harvested at extra- or intraoral locations (chin or retromolar area) (Misch, Misch, 1995; Monje, et al., 2015). Major drawbacks when using autogenous tissue is the morbidity associated with the harvesting procedure (Nkenke, et al., 2002) and the limited amount that can be obtained intraorally (Zeltner, Fluckiger, Hammerle, Husler, Benic, 2016). Techniques were continuously modified during the last 30 years (Tessier, et al., 2005). However, the data on primary augmentations with xenogeneic and alloplastic materials are scarce though (Sanz-Sanchez, Ortiz-Vigon, Sanz-Martin, Figuero, Sanz, 2015), probably due to the fact that with an increasing augmented volume, the integration of the material becomes more critical. In order to accelerate the integration of bone substitute materials, growth factors such as BMP-2 have

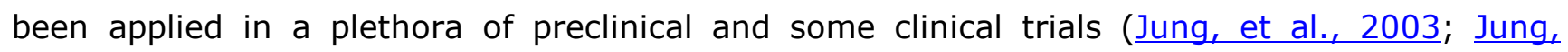
Thoma, Hammerle, 2008; Terheyden, Jepsen, Moller, Tucker, Rueger, 1999).

In the majority of the studies, the augmented volume following primary augmentation was assessed by using either a caliper or a periodontal probe (Cordaro, Torsello, Morcavallo, di Torresanto, 2011; Maiorana, Beretta, Salina, Santoro, 2005; von Arx, Buser, 2006; Widmark, Andersson, Ivanoff, 1997). More recently, non-invasive methods of analyses were introduced applying CBCTs (Benic, Bernasconi, Jung, Hammerle, 2017a; Buser, et al., 2013) and profilometric contour measurements (Thoma, et al., 2016). Whereas the CBCT allows measuring the amount of bone regenerated, the additional use of digital or conventional impressions allows assessing the impact of bone regenerative procedures on the soft tissue contour. 
The combination of $\mathrm{CBCT}$ and surface contour measurements therefore allows differentiating between ridge width changes at the level of the bone and the level of the mucosa. These methods might unfold more distinct and precise analysis of the applied treatment and the biological process of graft integration.

Therefore, the aim of the present study was to test whether or not, the use of a xenogeneic block loaded with rhBMP-2 results in superior ridge width at the level of the prospective implant shoulder at 4 months based on СBCT analysis and soft tissue contour based on profilometric outcome measures compared to the use of an autogenous bone block for primary bone augmentation. 


\section{Materials and methods}

The present exploratory, randomized, controlled clinical study was performed at the Clinic of Fixed and Removable Prosthodontics and Dental Material Science, University of Zurich, Zurich, Switzerland (center 1, 14 patients) and at the Department of Oral Surgery and Radiology, School of Dentistry, Medical University Graz, Graz, Austria (center 2, 10 patients). No comparable clinical data using similar augmentation materials and measurement techniques were available when the study was designed. Therefore, the study is considered to be of explorative nature. The clinical outcomes, histologic results and patient-reported outcome measures were reported earlier (Thoma, et al., 2017). Patients in need of implant therapy were consecutively enrolled. All sites presented an insufficient ridge width for implant placement of less than 5mm. The local ethical committee of Zurich (KEK-ZH-Nr. 2010-0213/5) and Graz (24372 ex 11/12) approved all procedures and materials. Informed consent was obtained from all participating patients.

Specific exclusion criteria:

- Pregnancy, intention to become pregnant, breast feeding, lack of safe contraception

- Medication with a contraindication for implant therapy

- Previous administration of InductOs $®$

- Skeletal immaturity

- Any active malignancy or patient undergoing treatment for a malignancy

- Persistent compartment syndrome or neurovascular residua of compartment syndrome

- Pathological fractures such as those observed in (but not limited to) Paget's disease or in metastatic bone

- Contraindications to the class of drugs under study, e.g. known hypersensitivity or allergy to class of drugs or the investigational product 
Specific inclusion criteria:

- Patients older than 18 years of age

- Good general health and no systemic disease

- Periodontally healthy (Bleeding on probing and plaque index $<25 \%$, no periodontal pockets exceeding $4 \mathrm{~mm}$ )

- $\quad$ Smoking $\leq 10$ cigarettes per day

- Partially edentulous and requiring implant therapy

- Insufficient ridge width $(<5 \mathrm{~mm})$ to place dental implants at $1-4$ sites in the maxilla or mandible

- Tooth extraction at the defect site at least 3 months ago

- At least one neighboring natural tooth to the defect site(s)

- Signed informed consent

\section{Procedure}

Patients were randomly assigned according to a computer generated list. At the day of treatment, the surgeon opened a sealed envelope in order to treat the patient either with a deproteinized bovine bone mineral (DBBM) block (Bio-Oss Spongiosa Block $®$, Geistlich Pharma AG, Wolhusen, Switzerland) infused with rh-BMP-2 (InductOs $®$, Medtronic BioPharma, Neuchâtel, Switzerland) (test), or with an autogenous bone block (control).

A first silicone impression of the site(s) including the neighboring teeth was taken at the screening visit before augmentation surgery (Pre Aug). The surgical procedures were described in detail previously (Thoma, et al., 2017). In brief, a paracrestal incision and oblique releasing incisions were placed, a full-thickness flap elevated and the cortical bone plate perforated at numerous locations. In the control group, an autogenous bone block was harvested from the symphysis or the retromolar area, depending on the donor site anatomy. In the test group, the DBBM block was moistened for 15 minutes with $1.2 \mathrm{ml}$ rhBMP-2 (InductOs ${ }^{2}$, rhBMP-2 concentration $1.5 \mathrm{mg} / \mathrm{ml}$ ). The xenogeneic blocks were then shaped and adapted to the defect (no screws were used). Autologous blocks were fixated with screws (GBR-System, Institute Straumann AG, Basel, Switzerland). Subsequently in both groups, a layer of xenogeneic bone 
particles (Bio-Oss Granulat ${ }$, Geistlich Pharma AG) was applied to cover the blocks and to fill up voids. The augmented area was then covered with a native collagen membrane (BioGide ${ }^{\circ}$, Geistlich Pharma AG). The membrane was immobilized by resorbable fixation pins (Inion GTR Tack ${ }$, Inion, Tampere, Finland). Following tension-free wound closure, a CBCT scan of the recipient site was taken (Post Aug). At suture removal (7-10 days later), a second silicone impression was taken (SR).

The second CBCT scan and the third silicone impression were taken prior to re-entry surgery, 4 months after the ridge augmentation surgery before implant placement (Pre IP). Subsequently, implants were placed according to the manufacturer's instruction (Astra Osseospeed TX, Astra Tech Implant System, Dentsply Sirona, York, United States) and in a prosthetically ideal position. Additional GBR procedures were performed in case of dehiscence or fenestration defects at the implants. Baseline examination for the follow-up including a third CBCT scan was performed 4-6 weeks after crown insertion (Post CI). All interventions and measurements are summarized in Figure 1.

\section{CBCT measurements}

In patients with more than one prospective implant site, the most mesial site was always included for the analysis. All measured sites correspond to those that had previously been clinically and histologically examined (Thoma, et al., 2017). CBCT scans were taken using two different scanners: a Kavo 3D eXam scanner (Kavo Dental GmbH, Biberach, Germany) at center 1 and a Planmeca romexis scanner (Planmeca Oy, Helsinki, Finland) at center 2. The settings for the field of view were between $160 \times 40 \mathrm{~mm}$ and $160 \times 80 \mathrm{~mm}$ (in order to obtain the full jaw for proper superimposition), $5 \mathrm{~mA}$ and $12 \mathrm{~mA}, 120 \mathrm{kV}$ and $84 \mathrm{kV}$, voxel size of $0.25 \mathrm{~mm}$ and $0.2 \mathrm{~mm}$ and an exposure time of 4 and 12 seconds respectively. The dicom data files were saved as a set of single frames and were then imported into an image analysis software (3D Slicer, http://www.slicer.org). All three CBCT scans were manually superimposed roughly. The volume was then cropped to further facilitate the superimposition, keeping distinct reference structures as well as the region of interest. The scans were then registered and superimposed 
automatically, followed by a visual accuracy check. Finally, the Post CI scan, containing the implant within the image, was used to choose a cross-section. The cross-section was chosen along the center axis of the implant (Figures 2 a-c). The cross-sections of all three scans, containing a scale in $\mathrm{mm}$ were saved and imported into a raster graphics editor (Adobe Photoshop CS13, Adobe Systems Incorporated, San Jose, USA). A grid was placed on the Post CI scan with a vertical line adjusted to the implant axis, and a horizontal line adjusted to the implant shoulder. Further horizontal lines at an interval of $1 \mathrm{~mm}$ determined the horizontal ridge width measurements until $5 \mathrm{~mm}$ below the implant shoulder. The grid was adjusted according to the scale and was then copied onto the cross-sections of the Post Aug and Pre IP scan, translating the (future) implant position by means of the grid onto these scans (Figures $2 d-f$ ). Measurements were performed using a further image analysis software (imageJ, National Institutes of Health). The scale was used to calibrate the software for every cross-section separately and the measurements were performed along the grid placed before.

Horizontal measurements:

- Ridge width (RW, mm): RW was measured at the level of the implant shoulder (IS) and at 2 and $5 \mathrm{~mm}$ below the IS. On the Post Aug scan, the RW of the native and of the augmented bone was measured separately. On the Pre IP scan, the entire RW was measured as the border between native and augmented bone could not be precisely differentiated anymore.

Augmented area:

- The area of augmented bone $\left(\mathrm{AA}, \mathrm{mm}^{2}\right)$ was marked in the Post Aug cross-section (Figure $2 \mathrm{~g}$ ) and transferred onto the corresponding, superimposed Pre IP cross-section. There, the area was reduced along the buccal contour according to the situation at 4 months (Figure $2 \mathrm{~h}$ ). The difference between the two areas $\left(\mathrm{mm}^{2}\right)$ was then calculated (Figure 2i).

\section{Profilometric measurements based on impressions}


Impressions were taken at the screening visit (Pre Aug), at suture removal (SR) and at 4 months, prior to implant placement (Pre-IP). Subsequently, all casts were scanned at center 1 with a desktop scanner (Imetric 3D, Courgenay, Switzerland). The obtained stereolithographic files (Standard tessellation language, STL format) were uploaded into a software for volumetric and profilometric analysis (Swissmeda software, Swissmeda, Zurich, Switzerland). The STL surfaces were superimposed using reference structures, which did not change over time, neighboring teeth predominantly. A cross-section, representing the planned implant position was selected.

Profilometric measurement:

- A crestal region of interest (ROI) was selected on the baseline surface, with a mesiodistal extension according to the implant site. The bucco-oral dimension was drawn with a distance of $1 \mathrm{~mm}$ from the buccal crest and extended $4 \mathrm{~mm}$ to the palatal/lingual side.

- The buccal ROI was again selected on the baseline surface, with a similar mesio-distal extension. The apico-coronal dimension was defined with a coronal border $1 \mathrm{~mm}$ below the buccal crest and an apical extension of $5 \mathrm{~mm}$.

The software then calculated the mean distance $(M D, m m$ ) between the surfaces within the ROI (Figure 3+4).

\section{Statistical analysis}

The data was collected in Excel (Microsoft Corporation, Redmond, Washington, USA) and statistical analysis was performed with SAS 9.4 (SAS Corp., Cary NC. USA). Mean, median, standard deviation and the range were used to describe continuous variables as well as counts and percentages were used for categorical variables. The comparison of the treatments and possible confounding factors as centers and sites were analyzed with Wilcoxon-signed rank test, Mann-Whitney test or nonparametric ANOVA models because of the small sample size and the non-normality of the data. The primary endpoint is the ridge width at the implant shoulder. Because of multiple testing of all variables, a Bonferroni correction was applied and the level of statistical significance was set at 0.0008 to compare the two groups. For the primary endpoint, 
nonparametric $90 \%$ confidence intervals were derived for the median of the differences of the two groups to comment possible equivalence of the two groups. 


\section{Results}

In 23 out of 24 patients originally included, the augmentation procedure was considered to be successful, allowing to place dental implants 4 months later. In one patient in the control group, the augmentation procedure failed with the autogenous bone block being exposed 6 days after surgery. Due to an ineffective antiseptic treatment, the block had to be removed after 21 days to allow for adequate wound healing. Since the patient with the failed augmentation refused to undergo another surgical procedure, he was excluded from the present study. According to the protocol, this patient was replaced by an additional patient receiving an autogenous bone block. The median age at the screening visit was 58.0 years (Q1 $=44 ; \mathrm{Q} 3=66)$ in the test group and 46.5 years $(\mathrm{Q} 1=34 ; \mathrm{Q} 3=61.5)$ in the control group. Descriptive data are presented in table 1 . The stated $p$-values beyond the primary outcome (ridge width at the implant shoulder at 4 months) are considered explorative.

\section{CBCT measurements}

Ridge width (RW, $\mathrm{mm}$ ) at the height of the prospective implant shoulder (IS)

The median RW after augmentation (Post Aug) amounted to $7.13 \mathrm{~mm}(\mathrm{Q} 1=6.02 ; \mathrm{Q} 3=8.47$; test $)$ and $6.86 \mathrm{~mm}(\mathrm{Q} 1=5.99 ; \mathrm{Q} 3=8.95$; control $)$, whereas the width of the native bone was $2.03 \mathrm{~mm}(\mathrm{Q} 1=0.80 ; \mathrm{Q} 3=4.03 ;$ test $)$ and $2.78 \mathrm{~mm}(\mathrm{Q} 1=1.37 ; \mathrm{Q} 3=3.27$; control $)$. The gain due to the augmentation was statistically significant in both groups $(p=0.0005 / p=0.0005)$. From Post Aug to Pre IP, the total RW decreased statistically significantly and amounted to 5.35 $\mathrm{mm}(\mathrm{Q} 1=4.53 ; \mathrm{Q} 3=6.7)$ for the test and $5.15 \mathrm{~mm}(\mathrm{Q} 1=3.57 ; \mathrm{Q} 3=7.24)$ for the control group $(p=0.0005 / p=0.0005)$. The differences between the groups were not statistically significant ( $p>0.5899)$. For commenting possible equivalence, the Hodges Lehmann estimate of the median of differences and corresponding $90 \%$ confidence intervals amounted to $-0.2 \mathrm{~mm}$ $[-1,86 ; 1.28]$ at Post Aug and $-0.45 \mathrm{~mm}[-2.10 ; 0.79]$ at Pre IP.

Ridge width (RW, $\mathrm{mm}) 2 \mathrm{~mm}$ below the prospective implant shoulder (IS) 
After augmentation, a total ridge width of $9.88 \mathrm{~mm}(\mathrm{Q} 1=8.98 ; \mathrm{Q} 3=10.47$; test $)$ and 8.63 $\mathrm{mm}(\mathrm{Q} 1=6.37 ; \mathrm{Q} 3=10.35 ;$ control $)$ was obtained. The median ridge width of the native bone was $3.58 \mathrm{~mm}(\mathrm{Q} 1=2.71 ; \mathrm{Q} 3=5.23$; test $)$ and $3.26 \mathrm{~mm}(\mathrm{Q} 1=2.33 ; \mathrm{Q} 3=4.03$; control $)$. The gain due to the augmentation was statistically significant in both groups $(p=0.0005 / p=0.0005)$. From Post Aug to Pre IP, a statistically significant decrease to a total RW of $7.86 \mathrm{~mm}(\mathrm{Q} 1=$ $6.74 ; \mathrm{Q} 3=9.09)$ for the test and $7.20 \mathrm{~mm}(\mathrm{Q} 1=5.86 ; \mathrm{Q} 3=8.83)$ for the control group was measured $(p=0.0005 / p=0.0005)$. Again, the differences between the groups were not statistically significant $(p>0.1277)$.

Ridge width (RW, $\mathrm{mm}) 5 \mathrm{~mm}$ below the prospective implant shoulder (IS)

A total RW of $10.96 \mathrm{~mm}(\mathrm{Q} 1=10.62 ; \mathrm{Q} 3=11.64 ;$ test $)$ and $9.32 \mathrm{~mm}(\mathrm{Q} 1=6.97 ; \mathrm{Q} 3=$ 11.20; control) was obtained Post Aug. The according native RW was $5.28 \mathrm{~mm}(\mathrm{Q} 1=4.12$; Q3 =9.24; test $)$ and $4.72 \mathrm{~mm}(\mathrm{Q} 1=3.45 ; \mathrm{Q} 3=6.92$; control $)$. The ridge width gained due to the augmentation was again statistically significant in both groups $(p=0.0005 / p=0.0005)$. A statistically significant $(p=0.0005 / p=0.0005)$ decrease from Post Aug to Pre IP was found with a total RW of $9.73 \mathrm{~mm}(\mathrm{Q} 1=9.18 ; \mathrm{Q} 3=10.75)$ for the test and $8.27 \mathrm{~mm}(\mathrm{Q} 1=5.69 ; \mathrm{Q} 3=$ 10.13) for the control group at Pre IP. The inter-group differences were not statistically significant $(p>0.0597)$.

Augmented area $(A A, \%)$

The decrease of the AA from Post Aug to Pre IP amounted to $-13.88 \%(\mathrm{Q} 1=-25.44 ; \mathrm{Q} 3=-$ 6.94) for the test and $-25.62 \%(\mathrm{Q} 1=-34.11 ; \mathrm{Q} 3=-20.67)$ for the control group. With the applied Bonferroni correction, the difference was not statistically significant $(p=0.0173)$.

\section{Profilometric measurements based on impressions}

Over the entire observation period (Pre Aug - Post CI), a slight gain was measured buccally for test $(0.83 \mathrm{~mm} ; \mathrm{Q} 1=0.62 ; \mathrm{Q} 3=1.87)$ and control $(1.16 \mathrm{~mm} ; \mathrm{Q} 1=0.50 ; \mathrm{Q} 3=1.44)$ on the level of the soft tissues. Values for the occlusal measurements amounted $-0.03 \mathrm{~mm}(\mathrm{Q} 1=-$ 
$0.57 ; \mathrm{Q} 3=0.79)$ for the test and $-0.29 \mathrm{~mm}(\mathrm{Q} 1=-0.67 ; \mathrm{Q} 3=0.63)$ for the control group. There were no statistically significant differences between the groups ( $p>0.4134)$.

Data were further tested for possible effects such as center, side, anterior (including canines) versus posterior (premolars and molars) and upper versus lower jaw. They were not statistically different if multiple testing was corrected, except for ridge width at $5 \mathrm{~mm}$ at 4 months, when comparing upper versus lower jaw $(p=0.0002)$. Measurements showed generally higher values for the upper jaw, actually a finding, which was noticed for all RW variables. 


\section{Discussion}

The present two-center study assessing two primary horizontal bone augmentation techniques revealed that i) both treatment modalities significantly increased the ridge width at all measured levels below the crest and allowed dental implant placement at 4 months; ii) the augmented area demonstrated a higher, however not statistically significant, decrease in the control than in the test group; iii) the two bone regenerative procedures had only a minor impact on the soft tissue contour.

Biologic mediators with a high osteogenic potential (e.g. rhBMP-2) have been frequently used for bone regenerative procedures in preclinical studies and with restricted indications in clinical experimental trials so far. One of the major drawbacks when using rhBMP-2 was the combination with a carrier material, as predominantly, collagen matrices with no space maintenance were used (Barboza, et al., 2000). In a clinical study applying rhBMP-2 in combination with a collagen sponge and tenting screws (Edmunds, et al., 2014), a mean horizontal gain of $1.2 \mathrm{~mm}$ was calculated. The latter study, however, also indicated that the use of tenting screws and a collagen sponge as a scaffold material might not provide sufficient space maintenance. In the present study, the test group revealed a higher gain of ridge width (3-4mm), probably attributed to the space maintaining function of the xenogeneic block material as such. The type of defects being augmented appears to be similar in both studies (the present and the cited previous one). Therefore, the xenogeneic block material seems to be a valid candidate to support space maintenance over time. Previous studies demonstrated a similar stability of the same xenogeneic bovine bone block when assessing the effect of wound closure on volume stability of an augmented site (Mir-Mari, Wui, Jung, Hammerle, Benic, 2016), in case of lateral bone augmentation at implant sites (Benic, et al., 2017b) and for primary bone augmentation without the addition of a growth factor (Hammerle, Jung, Yaman, Lang, 2008). The latter study also demonstrated that primary bone augmentation can be obtained using the same xenogeneic block material, but healing times of up to 9-10 months were required. In contrast, the addition of rhBMP-2 in the present study allowed to shorten the 
healing period to 4 months without the risk of losing the augmented bone substitute material (Thoma, et al., 2017). Clinical and radiographic observations revealed that the xenogeneic bone block material was in tight contact with the underlying bone in a chronic ridge defect. In some clinical cases the implants were placed in the center between the native bone and the augmented bone. In these cases, the drilling procedure to place the implant revealed a high stability of the entire augmented site. This clinical observation might be attributed to rhBMP- 2 being an effective promoter of bone regeneration. Similar observations were also made in a case series performing primary augmentation with allogeneic blocks in combination with rhBMP-2 (Misch, 2017).

The resorption and remodeling processes during the healing period remain one of the challenges when augmenting bone. Some autogenous bone blocks were reported to have resorption rates of the grafting material of up to $60 \%$ (Widmark, et al., 1997). There is evidence that cortical bone resorbs to a smaller extent compared to cancellous bone (Ozaki, Buchman, 1998). Beside the surgical effort, this fact favors intraoral donor sites. The technique was further modified by adapting developments made in terms of guided bone regeneration (GBR). The use of deproteinized bovine bone mineral (DBBM) to cover the bone block together with the application of a collagen membrane did indeed reduce the amount of resorption to roughly $10 \%$ (Cordaro, et al., 2011; Maiorana, et al., 2005; von Arx, Buser, 2006). Integration and the following slow resorption as well as volume stability of DBBM is well documented (Araujo, Sonohara, Hayacibara, Cardaropoli, Lindhe, 2002; Jensen, et al., 1996). The resorption rate in the present investigation was slightly higher with $25 \%$ in the control group within the first 4 months as compared to the aforementioned studies. However, comparing the two groups, the test group revealed a lower resorption rate, although this was not statistically significant with the applied bonferroni correction. The lower resorption rate might rather be attributed to the xenogeneic bone substitute rather than to the use of a growth factor, although this remains a speculation at this stage.

Ridge augmentation on the hard tissue level aims to regenerate a sufficient amount of bone to allow for dental implant placement. From a clinical point of view, one likes to regenerate the 
entire ridge contour allowing for improved esthetics as well. The present study revealed that the ridge contour as assessed by profilometric outcome measures increased over 4 months, not vertically, but rather on the buccal aspect. One has to bear in mind that the augmentations were predominantly performed in a horizontal dimension. Interestingly, when analyzing the buccal ROI, the increase was roughly $1 \mathrm{~mm}$ in both groups. The increase on the hard tissue level was roughly $4 \mathrm{~mm}$. This indicates that, whereas hard tissue augmentation was sufficient to place dental implants, changes on the soft tissue contour were affected to a very limited extent only. When looking at cross-sections with combined radiological and profilometric information, it becomes obvious that the ROI on the buccal aspect was located on a much more coronal level than the region where hard tissue was regenerated and measured. From an esthetic point of view and in order to regenerate the lost contour, soft tissue augmentation surgeries might still remain necessary in these cases. Similar conclusions were drawn in a case series including 16 patients (Schneider, Grunder, Ender, Hammerle, Jung, 2011).

Compared to the clinical measurements assessing the ridge width, the current measurements based on $\mathrm{CBCT}$ data might have some advantages. First, the scan after crown insertion was used to define the cross-section. Superimposition allowed to measure exactly at the (future) implant position, whereas clinically, especially in case of several neighboring sites, the mesiodistal position is difficult to define and predominantly to reproduce. CBCT scans can be superimposed with a high accuracy and enable to measure at a similar position (Koerich, Burns, Weissheimer, Claus, 2016). Secondly, the top of a ridge is always round and clinically it is up to the examiner on which level he is going to measure the ridge width. Here again, the implant shoulder of the future implant was used to define the height of measurement. Compared to the clinical measurements, this might have led to a measurement taken more apically as implants are always placed deeper than the top of a ridge. Comparing the radiological and clinical measurements, they are well in line except for one variable, the native ridge width. Clinically, the median native ridge width was higher for the test group and radiologically it was the opposite. This difference might be explained by the above mentioned technical differences, especially the vertical position of the performed measurement. 
The present outcomes are limited due to the small number of patients, the short observation period of 4 months and due to limited comparable data obtained with similar techniques based on $\mathrm{CBCT}$ measurements. In cases with multiple implants, the most mesial site was evaluated, with the rationale that the sites become more challenging for regeneration in the anterior region. However, one would expect the largest gain in ridge width in the center of the edentulous area. Maybe even more relevant is the fact that rhBMP-2 is rarely available for this indication depending on the geographic region, and the two materials are not available as a combination product. Furthermore, the cost-benefit ratio is still unfavorable if rhBMP-2 is derived from the medical field, as the doses are too large for dental indications and therefore the prices are too high. 


\section{Conclusions}

Both treatment modalities successfully increased the ridge width to a similar extent. The shrinkage during healing was not greater in the test than in the control group. The soft tissue contour remained stable comparing pre-surgery and 4 months and was only minimally influenced by hard tissue augmentation. 
Figure legend

Table 1 Descriptive values of all measured variables. $\mathrm{N}=$ number, $\mathrm{Std}=$ standard deviation, Min = minimum, $\mathrm{Q} 1=25 \%$ quartile, $\mathrm{Q} 3=75 \%$ quartile, Max = maximum, $\mathrm{p}$ value = WilcoxonMann-Whitney Test; $\mathrm{BL}=$ baseline, $4 \mathrm{M}=$ four months, $\mathrm{RW}=$ ridge width at IS (implant shoulder), at $2 \mathrm{~mm}$ and at $5 \mathrm{~mm}$ below IS, RWn = native ridge width, $\mathrm{RWa}=$ augmented ridge width, dif = difference between baseline and four months, aug area dif = difference in augmented area $(B L-4 M)$, MDbuc $=$ mean distance buccal, $\mathrm{MDoc}=$ mean distance occlusal, PrePost $=$ difference between preoperative and postoperative, Pre4M $=$ difference between preoperative and four months.

Figure 1 Study flowchart showing treatment and corresponding hard and soft tissue measurements. Pre Aug $=$ Before augmentation; Post Aug $=$ After augmentation; SR $=$ Suture removal; Pre IP = Before implant placement; Post CI = After crown insertion.

Figure 2a-c The volumes are cropped and superimposed, containing exactly the same crosssection exactly in the same position and scale. (a) The first CBCT scan was taken after augmentation (Post aug). The native and augmented bone can clearly be distinguished. (b) The second CBCT scan was taken after 4 months prior to implant placement (Pre IP). (c) The Third CBCT scan was taken after crown insertion (Post CI).

Figure 2d-f A grid was placed in figure $f$ according to the implants horizontal and vertical position and then transferred to the earlier time-points $d$ and e. All ridge width (RW) measurements were carried out along the grid, calibrated by the scale at the bottom of each cross-section.

Figure 2g-i The augmented area was marked on the Post aug scan, illustrated in blue ( $\mathrm{g}$ ). Similarly, this was done on the Pre IP scan, marked in green (h). The remaining difference (blue) represents the resorption during the healing phase (i).

Figure 3 Superimposed soft tissue contour before augmentation (Pre Aug, yellow), at suture removal (SR, green) and at 4 months (Pre IP, grey). The occlusal and buccal areas of measurement are marked in black.

Figure 4 Cross-section at the implant site showing the buccal measurement area of the case shown in Figure 3. The changes between before augmentation (Pre Aug, yellow) and suture 
removal (SR, green) were measured as well as between suture removal (SR, green) and 4 months (Pre IP, grey). 


\section{References}

Adell, R., Lekholm, U., Grondahl, K., Branemark, P. I., Lindstrom, J. \& Jacobsson, M. (1990). Reconstruction of severely resorbed edentulous maxillae using osseointegrated fixtures in immediate autogenous bone grafts. International Journal of Oral and Maxillofacial Implants 5: 233-246.

Araujo, M. G., Sonohara, M., Hayacibara, R., Cardaropoli, G. \& Lindhe, J. (2002). Lateral ridge augmentation by the use of grafts comprised of autologous bone or a biomaterial. An experiment in the dog. Journal of Clinical Periodontology 29: 1122-1131.

Barboza, E. P., Duarte, M. E., Geolas, L., Sorensen, R. G., Riedel, G. E. \& Wikesjo, U. M. (2000). Ridge augmentation following implantation of recombinant human bone morphogenetic protein2 in the dog. Journal of Periodontology 71: 488-496. doi:10.1902/jop.2000.71.3.488 Benic, G. I., Bernasconi, M., Jung, R. E. \& Hammerle, C. H. (2017a). Clinical and radiographic intra-subject comparison of implants placed with or without guided bone regeneration: 15-year results. Journal of Clinical Periodontology 44: 315-325. doi:10.1111/jcpe.12665 Benic, G. I., Thoma, D. S., Jung, R. E., Sanz-Martin, I., Unger, S., Cantalapiedra, A. \& Hammerle, C. H. F. (2017b). Guided bone regeneration with particulate vs. block xenogenic bone substitutes: a pilot cone beam computed tomographic investigation. Clinical Oral Implants Research 28: e262-e270. doi:10.1111/clr.13011

Buser, D., Chappuis, V., Kuchler, U., Bornstein, M. M., Wittneben, J. G., Buser, R., Cavusoglu, Y. \& Belser, U. C. (2013). Long-term stability of early implant placement with contour augmentation. Journal of Dental Research 92: 176S-182S. doi:10.1177/0022034513504949 Cordaro, L., Torsello, F., Morcavallo, S. \& di Torresanto, V. M. (2011). Effect of bovine bone and collagen membranes on healing of mandibular bone blocks: a prospective randomized controlled study. Clinical Oral Implants Research 22: 1145-1150. doi:10.1111/j.16000501.2010.02093.x

Edmunds, R. K., Mealey, B. L., Mills, M. P., Thoma, D. S., Schoolfield, J., Cochran, D. L. \& Mellonig, J. (2014). Maxillary anterior ridge augmentation with recombinant human bone 
morphogenetic protein 2. International Journal of Periodontics and Restorative Dentistry 34: 551-557. doi:10.11607/prd.1737

Hammerle, C. H., Jung, R. E., Yaman, D. \& Lang, N. P. (2008). Ridge augmentation by applying bioresorbable membranes and deproteinized bovine bone mineral: a report of twelve consecutive cases. Clinical Oral Implants Research 19: 19-25. doi:10.1111/j.16000501.2007.01407.x

Jensen, S. S., Aaboe, M., Pinholt, E. M., Hjorting-Hansen, E., Melsen, F. \& Ruyter, I. E. (1996). Tissue reaction and material characteristics of four bone substitutes. International Journal of Oral and Maxillofacial Implants 11: 55-66.

Jung, R. E., Glauser, R., Scharer, P., Hammerle, C. H., Sailer, H. F. \& Weber, F. E. (2003). Effect of rhBMP-2 on guided bone regeneration in humans. Clinical Oral Implants Research 14: 556-568.

Jung, R. E., Thoma, D. S. \& Hammerle, C. H. (2008). Assessment of the potential of growth factors for localized alveolar ridge augmentation: a systematic review. Journal of Clinical Periodontology 35: 255-281. doi:10.1111/j.1600-051X.2008.01270.x

Keller, E. E., Tolman, D. E. \& Eckert, S. (1999). Surgical-prosthodontic reconstruction of advanced maxillary bone compromise with autogenous onlay block bone grafts and osseointegrated endosseous implants: a 12-year study of 32 consecutive patients. International Journal of Oral and Maxillofacial Implants 14: 197-209.

Koerich, L., Burns, D., Weissheimer, A. \& Claus, J. D. (2016). Three-dimensional maxillary and mandibular regional superimposition using cone beam computed tomography: a validation study. International Journal of Oral and Maxillofacial Surgery 45: 662-669.

doi:10.1016/j.ijom.2015.12.006

Maiorana, C., Beretta, M., Salina, S. \& Santoro, F. (2005). Reduction of autogenous bone graft resorption by means of bio-oss coverage: a prospective study. International Journal of Periodontics and Restorative Dentistry 25: 19-25.

Mir-Mari, J., Wui, H., Jung, R. E., Hammerle, C. H. \& Benic, G. I. (2016). Influence of blinded wound closure on the volume stability of different GBR materials: an in vitro cone-beam 
computed tomographic examination. Clinical Oral Implants Research 27: 258-265.

doi: $10.1111 / \mathrm{clr} .12590$

Misch, C. M. (2017). Bone Augmentation Using Allogeneic Bone Blocks With Recombinant Bone Morphogenetic Protein-2. Implant Dentistry 26: 826-831. doi:10.1097/ID.0000000000000693 Misch, C. M. \& Misch, C. E. (1995). The repair of localized severe ridge defects for implant placement using mandibular bone grafts. Implant Dentistry 4: 261-267.

Monje, A., Monje, F., Hernandez-Alfaro, F., Gonzalez-Garcia, R., Suarez-Lopez del Amo, F., Galindo-Moreno, P., Montanero-Fernandez, J. \& Wang, H. L. (2015). Horizontal Bone Augmentation Using Autogenous Block Grafts and Particulate Xenograft in the Severe Atrophic Maxillary Anterior Ridges: A Cone-Beam Computerized Tomography Case Series. Journal of Oral Implantology 41 Spec No: 366-371. doi:10.1563/AAID-JOI-D-13-00219

Nkenke, E., Radespiel-Troger, M., Wiltfang, J., Schultze-Mosgau, S., Winkler, G. \& Neukam, F. W. (2002). Morbidity of harvesting of retromolar bone grafts: a prospective study. Clinical Oral Implants Research 13: 514-521.

Nystrom, E., Nilson, H., Gunne, J. \& Lundgren, S. (2009). A 9-14 year follow-up of onlay bone grafting in the atrophic maxilla. International Journal of Oral and Maxillofacial Surgery 38: 111116. doi:10.1016/j.ijom.2008.10.008

Ozaki, W. \& Buchman, S. R. (1998). Volume maintenance of onlay bone grafts in the craniofacial skeleton: micro-architecture versus embryologic origin. Plastic and Reconstructive Surgery 102: 291-299.

Rocchietta, I., Simion, M., Hoffmann, M., Trisciuoglio, D., Benigni, M. \& Dahlin, C. (2016). Vertical Bone Augmentation with an Autogenous Block or Particles in Combination with Guided Bone Regeneration: A Clinical and Histological Preliminary Study in Humans. Clinical Implant Dentistry and Related Research 18: 19-29. doi:10.1111/cid.12267 Sanz-Sanchez, I., Ortiz-Vigon, A., Sanz-Martin, I., Figuero, E. \& Sanz, M. (2015). Effectiveness of Lateral Bone Augmentation on the Alveolar Crest Dimension: A Systematic Review and Metaanalysis. Journal of Dental Research 94: 128S-142S. doi:10.1177/0022034515594780 Schneider, D., Grunder, U., Ender, A., Hammerle, C. H. \& Jung, R. E. (2011). Volume gain and stability of peri-implant tissue following bone and soft tissue augmentation: 1 -year results from 
a prospective cohort study. Clinical Oral Implants Research 22: 28-37. doi:10.1111/j.16000501.2010.01987.x

Terheyden, H., Jepsen, S., Moller, B., Tucker, M. M. \& Rueger, D. C. (1999). Sinus floor augmentation with simultaneous placement of dental implants using a combination of deproteinized bone xenografts and recombinant human osteogenic protein-1. A histometric study in miniature pigs. Clinical Oral Implants Research 10: 510-521.

Tessier, P., Kawamoto, H., Matthews, D., Posnick, J., Raulo, Y., Tulasne, J. F. \& Wolfe, S. A. (2005). Autogenous bone grafts and bone substitutes--tools and techniques: I. A 20,000-case experience in maxillofacial and craniofacial surgery. Plastic and Reconstructive Surgery 116: 6S-24S; discussion 92S-94S.

Thoma, D. S., Payer, M., Jakse, N., Bienz, S. P., Husler, J., Schmidlin, P. R., Jung, U. W., Hammerle, C. H. F. \& Jung, R. E. (2017). Randomized, controlled clinical two-centre study using xenogeneic block grafts loaded with recombinant human bone morphogenetic protein-2 or autogenous bone blocks for lateral ridge augmentation. Journal of Clinical Periodontology. doi: $10.1111 /$ jcpe. 12841

Thoma, D. S., Zeltner, M., Hilbe, M., Hammerle, C. H., Husler, J. \& Jung, R. E. (2016). Randomized controlled clinical study evaluating effectiveness and safety of a volume-stable collagen matrix compared to autogenous connective tissue grafts for soft tissue augmentation at implant sites. Journal of Clinical Periodontology 43: 874-885. doi:10.1111/jcpe.12588 von Arx, T. \& Buser, D. (2006). Horizontal ridge augmentation using autogenous block grafts and the guided bone regeneration technique with collagen membranes: a clinical study with 42 patients. Clinical Oral Implants Research 17: 359-366. doi:10.1111/j.1600-0501.2005.01234.x Widmark, G., Andersson, B. \& Ivanoff, C. J. (1997). Mandibular bone graft in the anterior maxilla for single-tooth implants. Presentation of surgical method. International Journal of Oral and Maxillofacial Surgery 26: 106-109.

Zeltner, M., Fluckiger, L. B., Hammerle, C. H., Husler, J. \& Benic, G. I. (2016). Volumetric analysis of chin and mandibular retromolar region as donor sites for cortico-cancellous bone blocks. Clinical Oral Implants Research. doi:10.1111/clr.12746 
